\title{
A Novel Optimization Method for Conventional Primary and Secondary School Classrooms in Southern China Considering Energy Demand, Thermal Comfort and Daylighting
}

\author{
Yizhe Xu ${ }^{1}$, Chengchu Yan ${ }^{2, *}$, , Hao Qian ${ }^{3}$, Liang Sun ${ }^{4}$, Gang Wang ${ }^{5}$ and Yanlong Jiang ${ }^{1}$ \\ 1 Key Laboratory of Aircraft Environment Control and Life Support, MIIT, Nanjing University of Aeronautics \\ and Astronautics, 29 Yudao Street, Nanjing 210016, China; dogxujy@outlook.com (Y.X.); \\ jiang-yanlong@nuaa.edu.cn (Y.J.) \\ 2 College of Urban Construction, Nanjing Tech University, No. 200 North Zhongshan Road, \\ Nanjing 210009, China \\ 3 Qinhuai Education Financial Assets Management Center, Nanjing 210002, China; putaoyuan@126.com \\ 4 Civil Aviation Management Institute of China, No. 3 Huajiadi East Road, Chaoyang District, \\ Beijing 100102, China; sunliang@camic.cn \\ 5 Nanjing Zhongyi Architectural Design Institute Co., Ltd., Nanjing 210009, China; sanlang75@126.com \\ * Correspondence: chengchu.yan@njtech.edu.cn
}

check for updates

Citation: Xu, Y.; Yan, C.; Qian, H.; Sun, L.; Wang, G.; Jiang, Y. A Novel Optimization Method for

Conventional Primary and Secondary School Classrooms in Southern China Considering Energy Demand, Thermal Comfort and Daylighting. Sustainability 2021, 13, 13119. https:// doi.org/10.3390/su132313119

Academic Editor: Cinzia Buratti

Received: 14 November 2021

Accepted: 23 November 2021

Published: 26 November 2021

Publisher's Note: MDPI stays neutral with regard to jurisdictional claims in published maps and institutional affiliations.

Copyright: (c) 2021 by the authors. Licensee MDPI, Basel, Switzerland. This article is an open access article distributed under the terms and conditions of the Creative Commons Attribution (CC BY) license (https:// creativecommons.org/licenses/by/ $4.0 /)$.

\begin{abstract}
The classroom environment is of great significance for the health of primary and secondary school students, but a comfortable indoor environment often requires higher energy consumption. This paper presents a multi-objective optimization method based on an artificial neural network (ANN) model, which can help designers efficiently optimize the design of primary and secondary school classrooms in southern China. In this optimization method, first, the optimization objectives and variables are determined according to building characteristics, and the physical model is established through simulation software (EnergyPlus) to generate the sample space. Second, sensitivity analysis is carried out for each optimization variable, and the physical model is modified according to the results to regenerate the sample space. Third, the ANN model is trained by using the regenerated sample space, and the Pareto optimal solution is generated through the use of the non-dominated sorting genetic algorithm II (NSGA-II). Finally, the effectiveness of the multi-objective optimization method is proven through a typical case of primary and secondary school classrooms in Nanjing, China. The results show that, compared with the benchmark scheme, TES decreased by $810.8 \mathrm{kWh}$ at most, PT increased by $47.8 \%$ at most and DI increased by $4.2 \%$ at most.
\end{abstract}

Keywords: envelop optimization; ANN; school classroom; multi-objective

\section{Introduction \\ 1.1. Background}

With the development of building environment technology, people's requirements for indoor comfort have become stricter [1]. Especially in schools, a healthy and comfortable indoor environment plays an important role in promoting students' learning efficiency and physical and mental health [2]. However, the creation of a good indoor environment requires considerable energy [3]. At present, the area of primary and secondary school buildings in China is approximately 1.7 billion $\mathrm{m}^{2}$, accounting for $15 \%$ of the national public building area, and the building energy consumption is approximately 20 million tons of standard coal per year, accounting for approximately $7 \%$ of national public building energy consumption [4]. Primary and secondary school students should stay in the classroom for at least eight hours every day. Their physical and mental health is the focus of school and family attention. Some studies have shown that a good daylighting environment helps to reduce students' myopia rate [5], while a comfortable thermal environment helps students concentrate and makes them energetic [6,7]. Therefore, classroom thermal comfort and 
natural lighting are of great significance to the health of these students. In China, the main goal of classroom design is to meet the required specifications. The design often relies on past design experience and fails to take into account various factors, which can easily lead to an unreasonable design (poor comfort or high energy consumption in the classroom). Thus, how to optimize the design of primary and secondary school classrooms so that they offer a comfortable indoor environment and have low operating energy consumption has become an attractive challenge for architectural designers.

\subsection{Literature Review}

\subsubsection{Parametric Design and Architectural Design Optimization}

In recent years, the concept of parametric design has attracted extensive attention from researchers in the field of architecture [8]. Parametric design uses rational thinking instead of subjective imagination to design, which makes people reacquaint themselves with the design rules [9]. Through the application of parametric design, architectural design optimization can be realized. Ascione et al. proposed a multi-objective optimization approach to address the design problem of the building envelope. By taking primary energy consumption, cost and thermal comfort as the optimization objectives, the design of a typical Italian residential building was optimized. The results provide valuable guidance for the reconstruction of Italian residential inventories to achieve energy efficiency and cost optimization [10]. Hu et al. analyzed the influence of different levels of envelope thermal performance on building energy consumption. By taking a public building in Beijing as the research object, the influence of external walls, roofs and windows on building energy performance was analyzed by DeST-c software (developed by Tsinghua University). The results show that the transfer coefficient of external windows had the greatest influence on the indoor heat load, followed by the roof and the external wall [11]. Zhai et al. proposed a multi-objective optimization method combining the non-dominated sorting genetic algorithm II (NSGA-II) with EnergyPlus (jointly developed by the Department of Energy and Lawrence Berkeley National Laboratory) to optimize the window design. This method considered the many variables involved in window design and optimized the indoor visual performance, thermal comfort and energy. This method can help designers obtain an optimal window design solution to minimize building energy consumption while simultaneously improving the indoor thermal environment and visual performance [12]. Chang et al. proposed a building envelope decision-making scheme that could satisfy multiple objectives under uncertain conditions while considering possible building envelope schemes. Considering the uncertainty of the existing building form, performance prediction and newly developed facade system, a multi-objective optimization model was established. The optimization model and framework proposed in the above study will help to provide a roadmap for transforming existing buildings into smart and sustainable building systems [13]. Pan et al. established an online interaction framework that could couple any MATLAB-based algorithm to the standard simulation software EnergyPlus. By taking a typical residential building model in Nanjing as an example, the feasibility of the online optimization framework was studied. The results show that the interactive optimization framework was simple and accurate and could be used as an effective tool for building performance design [14]. Zhu et al. used Rhino-Grasshopper to extract and establish the benchmark models of three rural building types in northern China and comprehensively considered the energy, indoor daylighting and thermal comfort of the three building types, and explored the influence of the early design of the building shape and window-to-wall ratio (WWR) on the above performance [15]. Although multi-objective optimization has been applied in architectural design optimization, it has mainly adopted a coupling calculation of the simulation software and optimization algorithm. The parameterized physical model of the building is established by simulation software, which is used as the objective function in the optimization algorithm, and the Pareto solution set is obtained according to the optimization objectives. This method is simple and easy to perform, but due to the limitation of the calculation time of the simulation software, it is limited in optimization 
calculations that involve more variables. Furthermore, it is difficult for this method to fully consider the multiple factors of architectural design optimization.

\subsubsection{Optimization of Educational Architecture Design}

Due to the special needs of young people in terms of learning and growth, the special focus of education buildings must be user comfort while using as little energy as possible [16]. Therefore, the design optimization approach of education buildings must be a multi-objective optimization approach, taking into account various factors at the same time. Different from other public buildings and residential buildings, the optimization of daylighting in education buildings must be considered. Many studies have shown that daylighting has a very important impact on the health and performance of students and teachers. The benefits of good daylighting include an increase in students' sociability and concentration [17], the creation of a less stressful environment for students [18], an improvement in academic performance [19] and a reduction in energy costs [20]. In addition, some studies have shown that a good daylighting environment helps to reduce the myopia rate of students [5]. Zhang et al. used simulation optimization tools to optimize the thermal comfort and lighting of school buildings in northern China. In their optimization analysis, a variety of passive design parameters were considered, including orientation, room depth and corridor depth, the window-to-wall ratio of different interfaces, glass material and shading type [21]. Acosta-Acosta et al. proposed a multi-objective optimization model to optimize the design of natural ventilation education buildings to maximize the satisfaction of occupants with human biological pollutants/body odor levels and minimize construction costs. The effectiveness of their optimization model was verified by a case study in Los Angeles, CA, USA [22]. For the renovation of education buildings in the Mediterranean region, Ascione et al. proposed a multi-step optimization method that enabled scientists, professionals and designers to optimize the energy-saving renovations of existing education buildings. The optimization process involves the renovation of the building envelope, the integration of heating, ventilation and air conditioning (HVAC) systems and a renewable energy supply. The optimization method can comprehensively consider costs, indoor comfort and energy and determine an optimal transformation scheme [23]. Bakmohammadi et al. proposed an optimization framework for classrooms in Tehran-Mehrabad, which could not only meet residents' comfort demands but also improve energy efficiency. With the help of parametric design, architects can obtain a set of effective methods for the best classroom design scheme from the Pareto front and then make the final decision according to their personal preferences by comparing the visual comfort of the best solution. The abovementioned study provides designers with a guideline for sustainable classroom design and encourages them to use innovative energy-saving methods [24]. There are great differences in the structure of educational buildings across different countries and regions, so it is difficult to find a general physical model. Therefore, the above research on the optimization of education buildings shows that strong regional characteristics exist. Moreover, the architecture characteristics of primary and secondary schools and universities are also very different. The inner corridor structure is often used in educational buildings in universities, and the classroom has only one side external window. The outer corridor structure is often used in primary and secondary school education buildings, and the external windows must be set on both sides of the classroom. Classrooms are the core of the optimization design of primary and secondary schools, and there are few studies on the optimization design of conventional primary and secondary school classrooms in southern China.

\subsubsection{Application of the Meta-Model in Architectural Design Optimization}

All the above mentioned optimization studies involve the application of computeraided optimization. Through the coupling of simulation software and an optimization algorithm, optimization research is carried out. However, evolutionary algorithms usually require many cost function evaluations to obtain satisfactory results [25]. In addition, as 
described in Section 1.2.1, the running time of simulation software greatly restricts the development of architectural design optimization in practical applications [26]. More importantly, due to the limitations of simulation software, some optimization indexes cannot be obtained directly by running the software and need to be reprocessed. Therefore, traditional computer-aided optimization faces difficulty in dealing with multi-objective optimization problems with many variables. To fully consider numerous variables and achieve more realistic multi-objective design optimization, some researchers have used meta-models instead of physical models (simulation software) [27]. Through the coupling of a meta-model and a multi-objective optimization algorithm, simulation efficiency is improved at the expense of a certain simulation accuracy. At present, the meta-model has been used in some design optimization studies. Wang et al. proposed a three-stage multiobjective optimization method for passive house design, which reduced model complexity, improved model efficiency and had strong engineering applicability. In the above study, gradient boosted decision trees were used, instead of a physical model, to optimize the passive performance of buildings [26]. Yu et al. proposed a new multi-objective optimization model to assist designers in green building design. The improved back propagation (BP) network based on a simulation optimized by the genetic algorithm was used to represent the building behavior. Then, the GA-BP network model was established to quickly predict the energy consumption and indoor thermal comfort of residential buildings [28]. Asadi et al. proposed a multi-objective optimization model based on the genetic algorithm and an artificial neural network, which could be used to quantitatively evaluate the technology selection of building renovation projects. The above model combined the rapidity of artificial neural network evaluation with the optimization ability of the genetic algorithm. By taking a school building as an example, the practicability of the proposed method was illustrated, and possible problems were noted [29]. Although the meta-model has been applied in the field of architectural design optimization, it has not been applied in the design optimization of primary and secondary school classrooms. Moreover, the prediction accuracy of the meta-model has a great influence on the optimization results, so it is of great significance to train a stable and high-precision meta-model.

\subsection{Research Gaps and Main Contributions}

According to the above analysis, a knowledge gap has been identified: an efficient multi-objective optimization method is needed for the classroom design of primary and secondary schools in southern China, which can meet the needs of researchers and designers in academic research and engineering applications. The design optimization of primary and secondary school classrooms needs to comprehensively consider daylighting, thermal comfort and energy. The variables involved in the optimization process are numerous and complex, making them of great research value. Therefore, this paper proposes a multi-objective optimization method based on a meta-model to achieve the Pareto optimal solutions of the design schemes of primary and secondary school classrooms in a short time. The remainder of this paper is arranged as follows. In the second section, an overall framework for the efficient multi-objective optimization method is proposed, and the implementation procedure of the method is introduced step by step. In the third section, the method is applied to practical classroom cases, and the results are analyzed. The last section concludes the paper.

\section{Methodology}

Figure 1 illustrates the framework of the proposed efficient multi-objective optimization method, which is divided into two modules: physical modeling and efficient optimization. The core of the physical modeling module is model establishment and sensitivity analysis, which is also the basis of the efficient optimization module. In the efficient optimization module, the coupling of the meta-model and optimization algorithm is used to achieve fast optimization, and the optimal scheme set is generated. This section details the involved methods. 


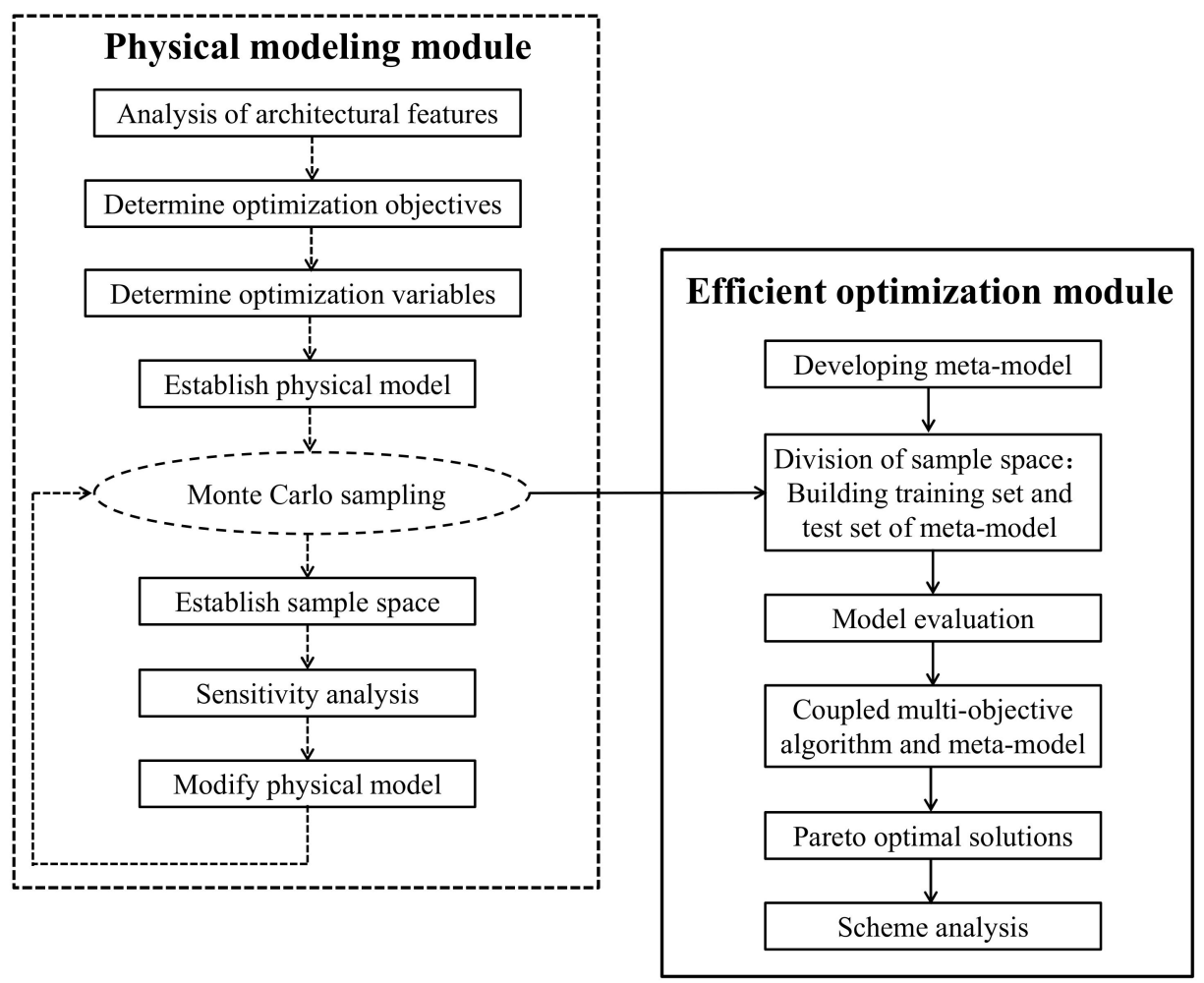

Figure 1. Framework for the multi-objective optimization method based on a meta-model.

\subsection{Physical Modeling}

\subsubsection{Optimization Objectives}

In the process of physical modeling, we first need to analyze the architectural features. The research objects of this paper are primary and secondary school classrooms in southern China, so the three indicators of thermal comfort, daylighting and energy are taken as the optimization objectives of this paper.

\section{Energy Performance Indicators}

The energy consumption of a classroom mainly includes lighting, heating and cooling, which are also closely related to each optimization objective. In this study, primary energy consumption is used to express annual lighting energy consumption (LES), annual heating energy consumption (HES), annual cooling energy consumption (CES) and total annual energy consumption (TES), as shown in Equations (1)-(4). The HVAC system of these classrooms is simplified as a variable-refrigerant-volume (VRV) air-conditioning system [29]. The mathematical model of the VRV system is built and developed based on the object of the existing air-cooled DX (direct expansion) coil in EnergyPlus [30]. This model determines the performance of the DX coil at part-load conditions, utilizing performance information at rated conditions along with curve fits for variations in total capacity, energy input ratio and part load fraction [31]. In this study, the full load cooling COP and full load heating COP in the DX coil model are set to be 3.25 and 3. With the change in indoor cooling/heating load, the COP value of real-time operation of the VRV system will also change. Per capita fresh air volume is considered in this study, and air volume is $30 \mathrm{~m}^{3} / \mathrm{h}$ according to the design specification [32].

$$
\begin{aligned}
\text { LES } & =\sum_{i=1}^{i=N l} \text { Les } \\
\text { HES } & =\sum_{i=1}^{i=N h} \text { Hes } \\
\text { CES } & =\sum_{i=1}^{i=N c} \mathrm{Ces}
\end{aligned}
$$




$$
\mathrm{TES}=\mathrm{LES}+\mathrm{HES}+\mathrm{CES}
$$

Les is the hourly lighting energy consumption in $\mathrm{kW}$; $\mathrm{Nl}$ denotes the annual lighting hours; Hes is the hourly heating energy consumption in $\mathrm{kW} ; \mathrm{Nh}$ denotes the annual heating hours; Ces is the hourly cooling energy consumption in $\mathrm{kW}$; and $\mathrm{Nc}$ denotes the annual cooling hours.

\section{Thermal Comfort Indicator}

PMV, indoor average air temperature and hours of thermal discomfort can be used as evaluation indicators of thermal comfort. PMV is a comprehensive evaluation indicator considering many relevant factors of human thermal comfort based on the basic human thermal balance, which shows the average index of the groups voting for $(-3 \sim 3)$ seven grades of thermal sensation [33]. According to reference [14], this study uses the proportion of thermal comfort duration (PT) to measure the indoor thermal comfort during the use period of buildings throughout the year. This indicator represents the percentage of the number of hours with PMV value within the range of -1 to 1 in the total number of hours in the use period of the whole year. The calculation process is shown in Equation (5).

$$
\mathrm{PT}=\frac{P t}{N O} \times 100 \%
$$

$P t$ is the number of hours when the indoor PMV value is greater than -1 and less than 1 during the whole year's building use period.

\section{Daylighting Indicator}

There are many indicators for evaluating visual performance, including the daylighting coefficient, illuminance, annual sun exposure [34], daylight glare probability [35] and so on [36]. According to [12], illuminance is selected as the indicator for measuring visual performance. The height of the working face in the classroom is $0.8 \mathrm{~m}$. During the use period, the hourly percentage of daylight illuminance greater than 500 lux on the working face (DI) is taken as the optimization objective of the visual performance evaluation.

$$
\mathrm{DI}=\frac{D i}{8760} \times 100 \%
$$

$D i$ is the number of hours when the daylighting illumination on the working face is greater than 500 lux during the use period of the whole year.

\subsubsection{Optimization Variables}

According to $[8,9,22,24]$ and the optimization objectives of the classroom determined in Section 2.1.1, the optimization variables of the classroom in this study are selected. The optimization variables involved are mainly envelope parameters, including the thermal conductivity of the wall, the solar absorptivity of the wall, the thickness of the wall, wall material density, wall specific heat, WWR, the U-value of the external window, the solar heat gain coefficient (SHGC) of the external window, the visible transmittance (VT) of the external window, the height and depth of the overhanging of the exterior window, orientation, cooling setpoint, heating setpoint, air tightness grade, etc.

\subsubsection{Establishment of a Physical Model and Sample Space}

After the optimization objectives and variables are determined, EnergyPlus software can be used to establish a physical model according to the building features. EnergyPlus is a building energy simulation engine jointly developed by the Department of Energy and Lawrence Berkeley National Laboratory. It can be used to simulate and analyze the heating, cooling, daylighting and ventilation of buildings. Due to the reliability of EnergyPlus software, many experts and scholars have used it to simulate building performance [37]. In the process of modeling, the features unrelated to the optimization variables can be 
simplified to reduce model complexity and uncertainty, and the various indicators involved in the optimization objectives can be used as the output parameters of the model. Then, the Monte Carlo method is used to generate the sample space.

\subsubsection{Sensitivity Analysis and Modified Physical Model}

After obtaining the sample space, sensitivity analysis is performed on the model, playing an important role in performance analysis, such as building energy, which can specifically extract the key factors that affect each building's performance [38]. The regression method is the most commonly used global sensitivity analysis method because it is easy to understand and the minimum sample size required is relatively small [39]. In this study, the least squares method was used as the regression analysis method. To further measure the relative importance of each optimization variable for each optimization objective, this study uses the standardized coefficient method [40] to deal with each independent variable (optimization variable) and dependent variable (optimization objective) before regression analysis.

The standardization coefficient subtracts the mean value of each variable, divided by the corresponding standard deviation. It is essentially a dimensionless operation. Suppose that there is a linear model with two variables; all variables are standardized according to Equations (7)-(9). In this case, the meaning of $\widetilde{\beta}_{1}$ is that $x_{1}$ changes one standard deviation and that y changes $\widetilde{\beta}_{1}$ by one standard deviation. When $\widetilde{\beta}_{1}$ is greater than $0, x_{1}$ is positively correlated with $y$, and when $\widetilde{\beta}_{1}$ is less than $0, x_{1}$ is negatively correlated with $y$. Therefore, the influence of each independent variable on the dependent variable can be judged by the absolute value of the standardized coefficient $(\widetilde{\beta})$.

$$
\begin{gathered}
\widetilde{y}=\frac{y-\bar{y}}{s \cdot d(y)} \\
\widetilde{x}=\frac{x-\bar{x}}{s \cdot d(x)} \\
y=x_{1} \beta_{1}+x_{2} \beta_{2}+\varepsilon \rightarrow \widetilde{y}=\widetilde{x}_{1} \widetilde{\beta}_{1}+\widetilde{x}_{2} \widetilde{\beta}_{2}+\widetilde{\varepsilon}
\end{gathered}
$$

$\tilde{y}$ is the standardization value of $y, \bar{y}$ is the mean of $y, s . d(y)$ is the standard deviation of $y, \widetilde{x}$ is the standardization value of $x, \bar{x}$ is the mean of $x, \operatorname{s.d}(x)$ is the standard deviation of $x, \beta$ is the coefficient before standardization, $\widetilde{\beta}$ is the standardization coefficient, $\varepsilon$ is the constant term before standardization and $\widetilde{\varepsilon}$ is the standardization constant term.

After sensitivity analysis, the influence of each independent variable on each dependent variable can be obtained. To improve the training quality of the follow up meta-model, we consider modifying the physical model (deleting the independent variables that have little influence on the three dependent variables). Then, the modified physical model is simulated by the Monte Carlo method, and the regenerated sample space is used for the training of the meta-model.

\subsection{Efficient Optimization \\ 2.2.1. Meta-Model}

A meta-model is an approximate model for studying complex input-output relationships exhibited by another more complex model (physics-based model) [41]. In the optimization of building performance, the commonly used meta-modeling techniques are polynomial regression, multivariate adaptive regression splines, Gaussian processes (GPs, also known as kriging), support vector machines (SVMs), and artificial neural networks (ANNs). Among them, ANN is the most widely used and performs well in building energy performance optimization [42]. It has an input layer of neurons that act as receivers, one or more hidden layers of neurons that compute the data and undergo iterations, and then an output layer that predicts the output, as shown in Figure 2 [43]. Therefore, the ANN model is used as the meta-model of efficient optimization in this study. 


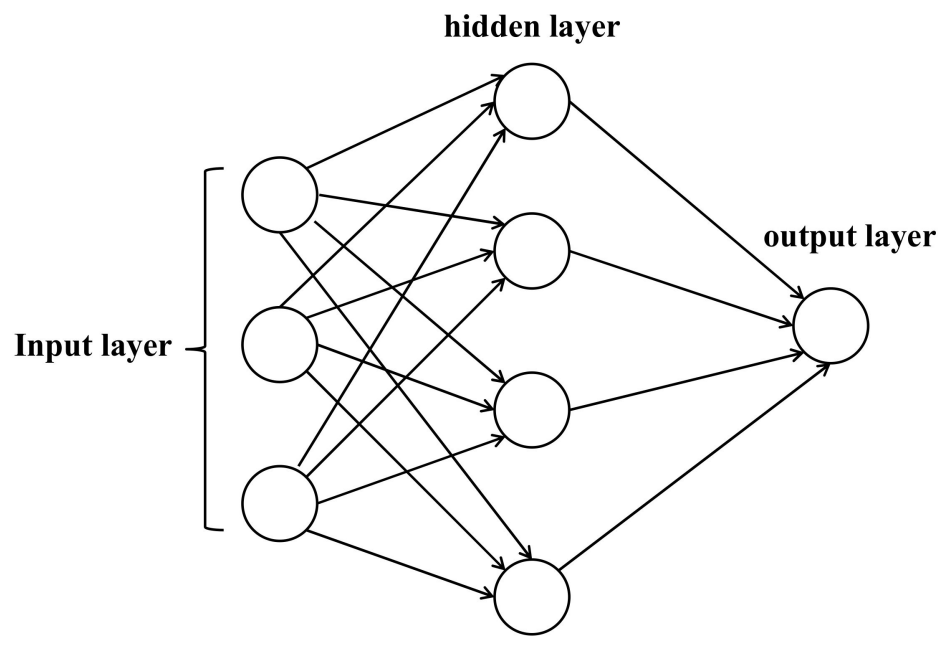

Figure 2. A typical ANN model.

\subsubsection{Division of Sample Space and Model Evaluation}

After determining the meta-model, it is necessary to divide the sample space. The sample space is usually divided into a training set and a test set. The training set is used to train the meta-model, and the test set is used to test the quality of the meta-model. In this study, the ratio of the training set to test set is 4:1.

The mean relative error is used to measure the accuracy of the meta-model. In this study, the meta-model has three output variables (corresponding to three optimization objectives: TES, PT and DI), and it is necessary to analyze the prediction accuracy of these three output variables. The robustness of the meta-model refers to its ability to provide acceptable accuracy for diverse problems with varying levels of complexity and dimensionality. Therefore, the meta-model technique must be robust to each output variable. According to [44], R2 is used as the measure of robustness.

\subsubsection{Multi-Objective Algorithm and Pareto Optimal Solutions}

In this study, three optimization objectives are included, the properties and dimensions of which are different. Thus, it is difficult to integrate them into an optimization function. Therefore, it is necessary to use a multi-objective algorithm to solve the problem and obtain the Pareto optimal solution set of the optimization problem, which lays the foundation for the subsequent decision-making process to choose the scheme according to preferences. There are many kinds of multi-objective algorithms, such as the multiobjective evolutionary algorithm, multi-objective particle swam optimization algorithm, non-dominated sorting genetic algorithm, non-dominated sorting genetic algorithm II (NSGA-II) and multi-objective simulated annealing algorithm. The NSGA-II is the most widely used multi-objective algorithm in terms of building performance optimization, and it performs well and stably in various fields [45]. Therefore, the NSGA-II is used as the multi-objective optimization algorithm in this study, and the ANN model selected in Section 2.2.1 is used as the objective function of the NSGA-II.

\subsubsection{Scheme Analysis}

In actual engineering applications, according to the needs of researchers or designers, the required scheme is selected in the Pareto optimal solutions. Due to the different needs of researchers or designers, the selection criteria are also different. For example, under the standard of ultralow energy consumption, priority will be given to the scheme with the best energy; under the standard of high requirements for thermal comfort, the scheme with the best thermal comfort will be selected. In this study, according to the three optimization objectives, the optimal scheme for each optimization objective will be analyzed. 


\section{Case Study}

To verify the effectiveness of the proposed multi-objective optimization method for the design optimization of primary and secondary school classrooms, this paper applies an optimization method to the design optimization of a typical school classroom in Nanjing, China. Python programming language, coupled with EnergyPlus, is used for simulation and optimization. Through the coupling of the program language and simulation software, the related contents of Monte Carlo simulation, sensitivity analysis and the efficient optimization module are realized.

\subsection{Case Information and Climate Characteristics}

The typical classroom structure in Nanjing is shown in Figure 3. Both sides A and $\mathrm{C}$ are usually internal walls, which are connected to other classrooms. Both sides B and $\mathrm{D}$ are external walls with external windows. Teaching buildings are generally multistory buildings, so the floor and ceiling of the classroom are connected with other classrooms. In this study, the floor and ceiling of the classroom are considered as internal walls. According to [46], the number of students in a typical classroom is considered to be 40 , and the per capita fresh air volume is set to $30 \mathrm{~m}^{3} / \mathrm{h}$.

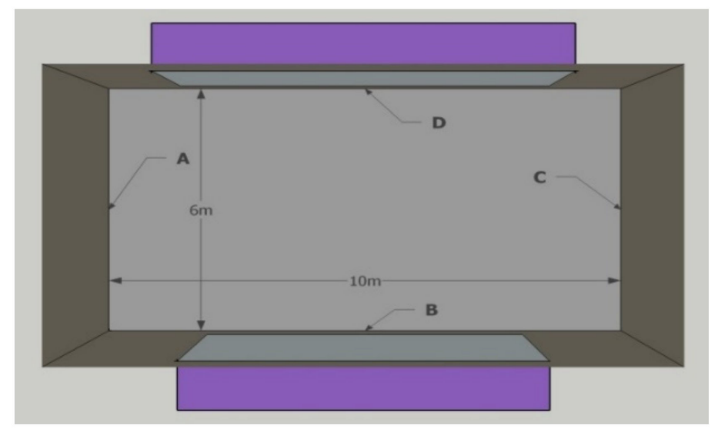

(a)

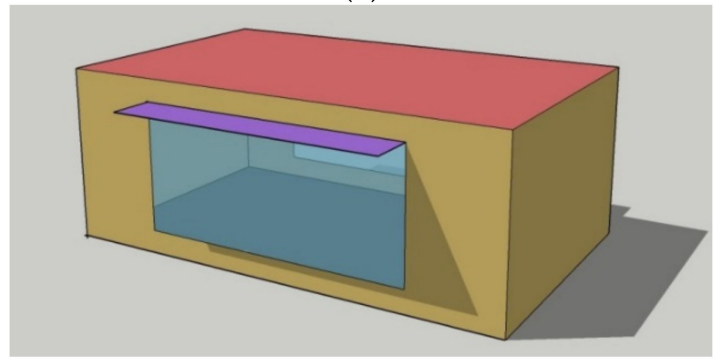

(b)

Figure 3. Schematic diagram of a typical classroom where: (a) is the top view of the classroom; (b) is the axonometric view of the classroom.

The geographical coordinates of Nanjing are $31^{\circ} 14^{\prime \prime}$ to $32^{\circ} 37^{\prime \prime} \mathrm{N}$ and $118^{\circ} 22^{\prime \prime}$ to $119^{\circ} 14^{\prime \prime}$ E. It has a subtropical monsoon climate, with abundant annual rainfall of $1200 \mathrm{~mm}$. The annual average temperature is $15.4^{\circ} \mathrm{C}$, and the annual extreme temperature is the highest at $39.7^{\circ} \mathrm{C}$ and the lowest at $-13.1^{\circ} \mathrm{C}$. The weather data for simulation are derived from the Chinese Standard Weather Data published on the EnergyPlus website [47].

\subsection{Classroom Modeling}

Section 3.1 introduces the architectural features of typical Chinese primary and secondary school classrooms. In this study, the physical model of the classroom is established by using EnergyPlus software. According to the relevant content of the optimization objectives and variables in Section 2.1, the optimization objectives in this study are thermal comfort, daylighting and energy. A total of 18 optimization variables are shown in Table 1. The value range and interval of variables refer to [10]. 
Table 1. Characterization of optimization variables.

\begin{tabular}{lcc}
\hline No. & Optimization Variables & Values \\
\hline X1 & Cooling setpoint $\left({ }^{\circ} \mathrm{C}\right)$ & $24 ; 25 ; 26 ; 27 ; 28$ \\
X2 & Heating setpoint $\left({ }^{\circ} \mathrm{C}\right)$ & $18 ; 19 ; 20 ; 21 ; 22$ \\
X3 & Solar absorptivity of wall $(-)$ & $0.1 ; 0.2 ; 0.3 ; 0.4 ; 0.5 ; 0.6 ; 0.7 ; 0.8 ; 0.9$ \\
X4 & Thickness of wall $(\mathrm{m})$ & $0.20 ; 0.25 ; 0.30 ; 0.35 ; 0.40$ \\
X5 & Thermal conductivity of wall $(\mathrm{W} / \mathrm{m} \cdot \mathrm{K})$ & $0.2 ; 0.3 ; 0.4 ; 0.5 ; 0.6 ; 0.7 ; 0.8 ; 0.9$ \\
X6 & Wall material density $\left(\mathrm{kg} / \mathrm{m}^{3}\right)$ & $1600 ; 1700 ; 1800 ; 1900 ; 2000$ \\
& & $500 ; 600 ; 700 ; 800 ; 900 ; 1000 ; 1100 ; 1200 ; 1300 ; 1400 ; 1500 ;$ \\
X7 & Wall specific heat $(\mathrm{J} /(\mathrm{kg} \cdot \mathrm{K}))$ & $100 ; 1500 ; 1600 ; 1700 ; 1800 ;$ \\
X8 & WWR of side B wall $(-)$ & $1900 ; 2000 ; 2100 ; 2200 ; 2300 ; 2400 ; 2500$ \\
X9 & WWR of side D wall $(-)$ & $0.2 ; 0.3 ; 0.4 ; 0.5 ; 0.6 ; 0.7 ; 0.8$ \\
X10 & U-value of external windows $\left(\mathrm{W} / \mathrm{m}^{2} \mathrm{~K}\right)$ & $0.2 ; 0.3 ; 0.4 ; 0.5 ; 0.6 ; 0.7 ; 0.8$ \\
X11 & SHGC of external windows $(-)$ & $0.8 ; 0.9 ; 1.0 ; 1.1 ; 1.2 ; 1.3 ; 1.4 ; 1.5$ \\
X12 & VT of external windows $(-)$ & $0.2 ; 0.3 ; 0.4 ; 0.5 ; 0.6$ \\
X13 & Overhanging depth of side B external window $(\mathrm{m})$ & $0.4 ; 0.5 ; 0.6 ; 0.7 ; 0.8$ \\
X14 & Overhanging height of side B external window $(\mathrm{m})$ & $0.1 ; 0.2 ; 0.3 ; 0.4 ; 0.5 ; 0.6 ; 0.7 ; 0.8 ; 0.9 ; 1.0 ; 1.1 ; 1.2 ; 1.3 ; 1.4 ; 1.5 ;$ \\
X15 & Overhanging depth of side D external window $(\mathrm{m})$ & $1.6 ; 1.7 ; 1.8 ; 1.9 ; 2.0$ \\
X16 & Overhanging height of side D external window $(\mathrm{m})$ & $0 ; 0.1 ; 0.2 ; 0.3 ; 0.4 ; 0.5$ \\
X17 & Orientation $\left({ }^{\circ}\right)$ & $0.1 ; 0.2 ; 0.3 ; 0.4 ; 0.5 ; 0.6 ; 0.7 ; 0.8 ; 0.9 ; 1.0 ; 1.1 ; 1.2 ; 1.3 ; 1.4 ; 1.5 ;$ \\
X18 & Air tightness $(1 / \mathrm{h})$ & $1.6 ; 1.7 ; 1.8 ; 1.9 ; 2.0$ \\
& & $0 ; 0.1 ; 0.2 ; 0.3 ; 0.4 ; 0.5$
\end{tabular}

According to the value range of each optimization variable, Monte Carlo simulation is used to generate the sample space. Then, the data of the sample space are used to analyze the sensitivity of each optimization variable. The sample size generated by Monte Carlo simulation has an impact on the results of the sensitivity analysis. To determine the impact of sample size on sensitivity analysis, this study uses different sample sizes.

The sensitivity analysis results of different sample sizes are shown in Figure 4, and the $R^{2}$ value of the regression model involved in the sensitivity analysis is shown in Table 2 . For different sample sizes, $\widetilde{\beta}$ is slightly different, but the overall trend is basically the same. With the increase in sample size, the $R^{2}$ value of each regression model is finally greater than 0.90 , which indicates that the regression model has strong robustness.

Table 2 . The determination coefficient $\left(R^{2}\right)$ of regression model in sensitivity analysis.

\begin{tabular}{cccccc}
\hline & Sample Size & Sample Size & Sample Size & Sample Size & Sample Size \\
& $\mathbf{3 0 0}$ & $\mathbf{5 0 0}$ & $\mathbf{1 0 0 0}$ & $\mathbf{2 0 0 0}$ & $\mathbf{3 0 0 0}$ \\
\hline TES & 0.904 & 0.927 & 0.934 & 0.931 & 0.926 \\
PT & 0.87 & 0.902 & 0.907 & 0.903 & 0.91 \\
DI & 0.802 & 0.914 & 0.923 & 0.917 & 0.926 \\
\hline
\end{tabular}

It can be seen from Figure $4 a$ that the cooling setpoint and heating setpoint have the greatest influence on the TES. The increase in the cooling setpoint and the decrease in the heating setpoint can significantly reduce the TES. Then, the wall thermal conductivity and wall thickness also have a great influence on the TES. The selection of wall materials with lower thermal conductivity and the increase in wall thickness can reduce the TES. In addition, air tightness also has a great impact on TES, and good air tightness can significantly reduce TES. The effects of wall specific heat, wall material density, orientation, the VT of external windows and the overhanging of external windows on the TES are relatively low. 


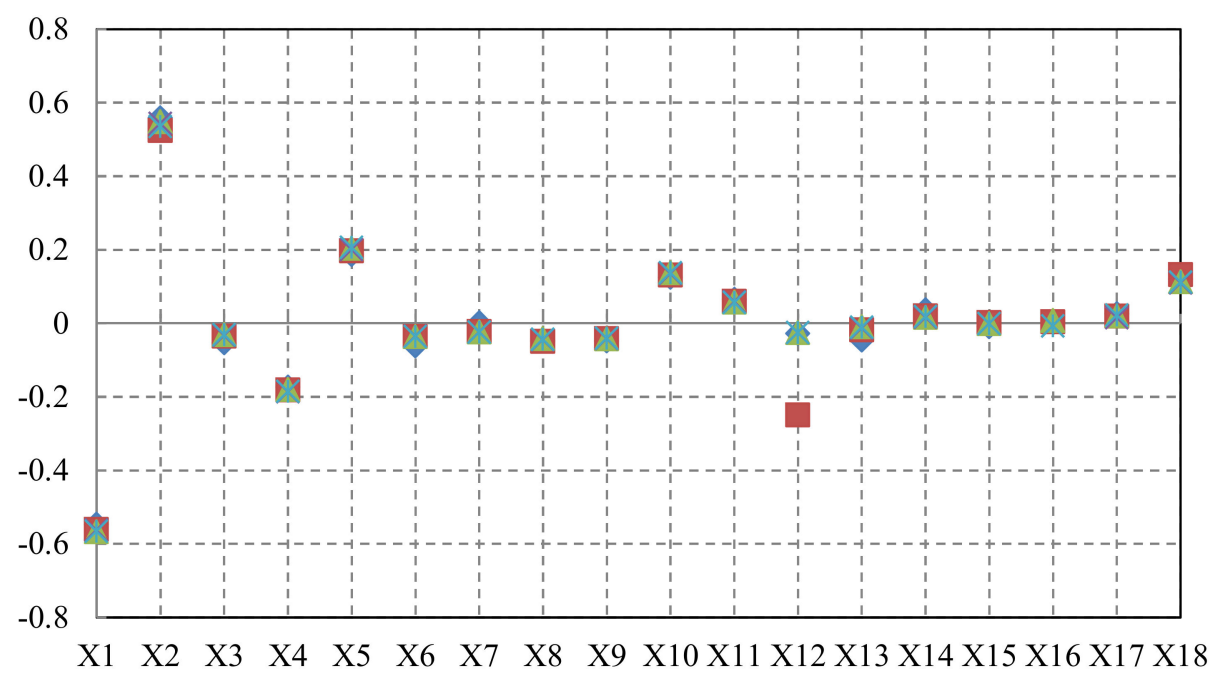

- Sample size 300

- Sample size 500

$\triangle$ Sample size 1000

$\times$ Sample size 2000

* Sample size 3000

(a)

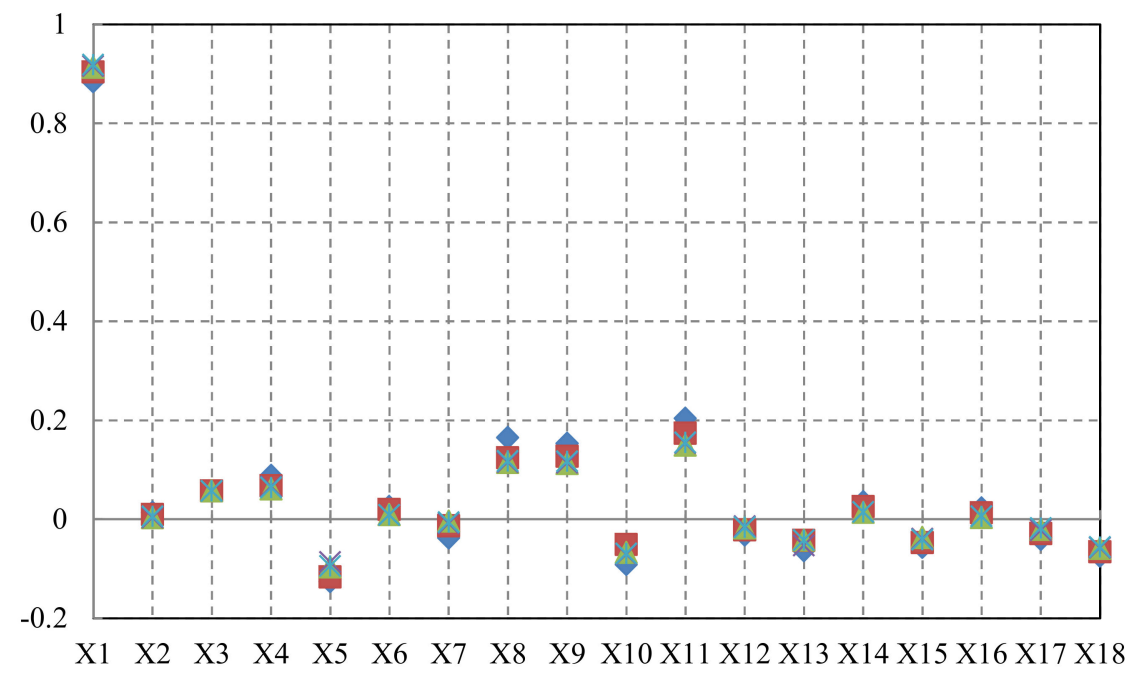

PT

- Sample size 300

- Sample size 500

$\triangle$ Sample size 1000

$\times$ Sample size 2000

* Sample size 3000

(b)

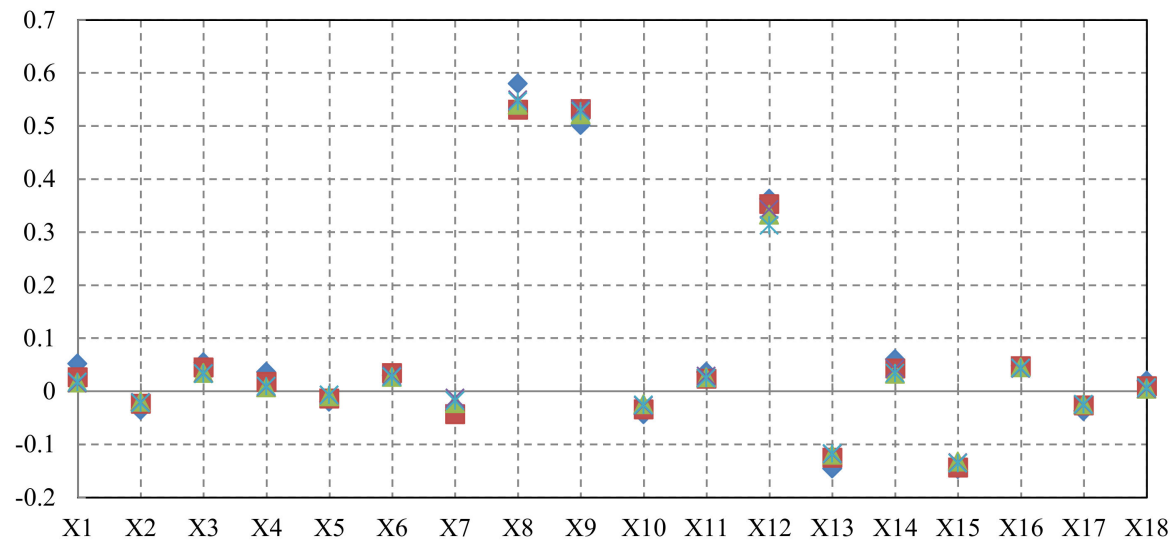

DI

- Sample size 300

口ample size 500

$\triangle$ Sample size 1000

$\times$ Sample size 2000

* Sample size 3000

(c)

Figure 4. Sensitivity analysis results of different sample sizes: the standardized coefficient $(\widetilde{\beta})$ of each optimization variable. (a) is the result of sensitivity analysis for TES; (b) is the result of sensitivity analysis for PT; (c) is the result of sensitivity analysis for DI.

Moreover, it can be seen from Figure $4 \mathrm{~b}$ that the cooling setpoint has the greatest influence on the PT, and increasing the cooling setpoint can significantly increase the PT. 
However, the heating setpoint has little influence on the PT. The SHGC of external windows and the WWR also have a great influence on the PT. Increasing these optimization variables can significantly increase the PT. Air tightness also has a certain impact on PT, and good air tightness helps to increase PT. Wall material density, wall specific heat, external window VT, overhanging height of external windows and orientation have little influence on the PT.

It can be seen from Figure 4c that the WWR has the greatest influence on the DI, and increasing the WWR can significantly increase the DI. The external window VT and overhang of the external windows have a great influence on the DI. Increasing these optimization variables can increase the DI. The relevant variables of the cooling setpoint, heating setpoint and wall have little influence on the DI.

In general, the impact of each optimization variable on the three optimization objectives is different, and contradictions exist. For example, the relevant variables of the wall have a greater impact on the TES and PT but a lesser impact on the DI. The overhanging of external windows has a great influence on the DI but little influence on the TES. These contradictions reflect the necessity for multi-objective optimization.

Figure 5 shows the sensitivity analysis results when the sample size is 3000 . According to the actual situation in this study, it is assumed that the absolute value of the standardization coefficient is less than $0.05(|\widetilde{\beta}|<0.05)$, indicating that the impact is low. Therefore, these optimization variables - wall material density, wall specific heat and orientation-have little influence on the three optimization objectives. To simplify the physical model and improve the training quality of the subsequent meta-model, in this paper, fixed values are used to replace the three optimization variables, and Monte Carlo simulation is carried out again to generate the sample space of the training meta-model.

$\begin{array}{rrrr} & \text { TES } & \text { PT } & \text { DI } \\ \text { X1 } & -0.57 & 0.91 & 0.00 \\ \text { X2 } & 0.55 & 0.00 & 0.00 \\ \text { X3 } & -\mathbf{0 . 0 3} & \mathbf{0 . 0 6} & \mathbf{0 . 0 0} \\ \text { X4 } & -\mathbf{0 . 1 8} & \mathbf{0 . 0 6} & \mathbf{0 . 0 1} \\ \text { X5 } & \mathbf{0 . 2 0} & -\mathbf{0 . 1 0} & -\mathbf{0 . 0 1} \\ \text { X6 } & \mathbf{- 0 . 0 4} & \mathbf{0 . 0 1} & \mathbf{0 . 0 0} \\ \text { X7 } & -\mathbf{0 . 0 2} & \mathbf{0 . 0 0} & \mathbf{0 . 0 0} \\ \text { X8 } & -\mathbf{0 . 0 4} & \mathbf{0 . 1 1} & \mathbf{0 . 5 4} \\ \text { X9 } & -\mathbf{0 . 0 4} & \mathbf{0 . 1 1} & \mathbf{0 . 5 2} \\ \text { X10 } & \mathbf{0 . 1 4} & -\mathbf{0 . 0 7} & \mathbf{0 . 0 0} \\ \text { X11 } & \mathbf{0 . 0 6} & \mathbf{0 . 1 5} & \mathbf{0 . 0 3} \\ \text { X12 } & -\mathbf{0 . 0 3} & -\mathbf{0 . 0 2} & \mathbf{0 . 3 3} \\ \text { X13 } & -\mathbf{0 . 0 1} & -\mathbf{0 . 0 4} & -\mathbf{0 . 1 2} \\ \text { X14 } & \mathbf{0 . 0 2} & \mathbf{0 . 0 1} & \mathbf{0 . 0 5} \\ \text { X15 } & \mathbf{0 . 0 0} & -\mathbf{0 . 0 4} & -\mathbf{0 . 1 3} \\ \text { X16 } & \mathbf{0 . 0 1} & \mathbf{0 . 0 0} & \mathbf{0 . 0 5} \\ \text { X17 } & \mathbf{0 . 0 2} & -\mathbf{- 0 . 0 2} & -\mathbf{0 . 0 2} \\ \text { X18 } & \mathbf{0 . 1 1} & -\mathbf{0 . 0 6} & \mathbf{0 . 0 0}\end{array}$

Figure 5. Sensitivity analysis results: the standardized coefficient $(\widetilde{\beta})$ of each optimization variable when the sample size is 3000 .

\subsection{Classroom Efficient Optimization}

3.3.1. Training and Evaluation of the ANN Model

According to Section 2.2.1, the ANN model is used as the meta-model in this study, and the schematic diagram of its input and output is shown in Figure 6. The setting of hyperparameters has an important influence on the accuracy of the meta-model. The most important hyperparameters affecting the ANN model include "activation function", "hidden layer sizes" and "hidden layer numbers". In order to determine the values of 
these important hyperparameters, the grid search algorithm is used to optimize these typical hyperparameters, and the results are shown in Table 3 . To determine the optimal sample size of the ANN model, we use different sample sizes for ANN model training. The ratio of the training set to the test set is $4: 1$. The mean relative error and $R^{2}$ values will be used to evaluate the ANN model, the results of which are shown in Table 4. With increasing sample size, the stability $\left(\mathrm{R}^{2}\right)$ of the ANN model is improved, and the accuracy is also increased (the mean relative error is reduced). When the sample size reaches 2000, the accuracy and stability of the ANN model perform well and can be applied to the subsequent multi-objective optimization algorithm.

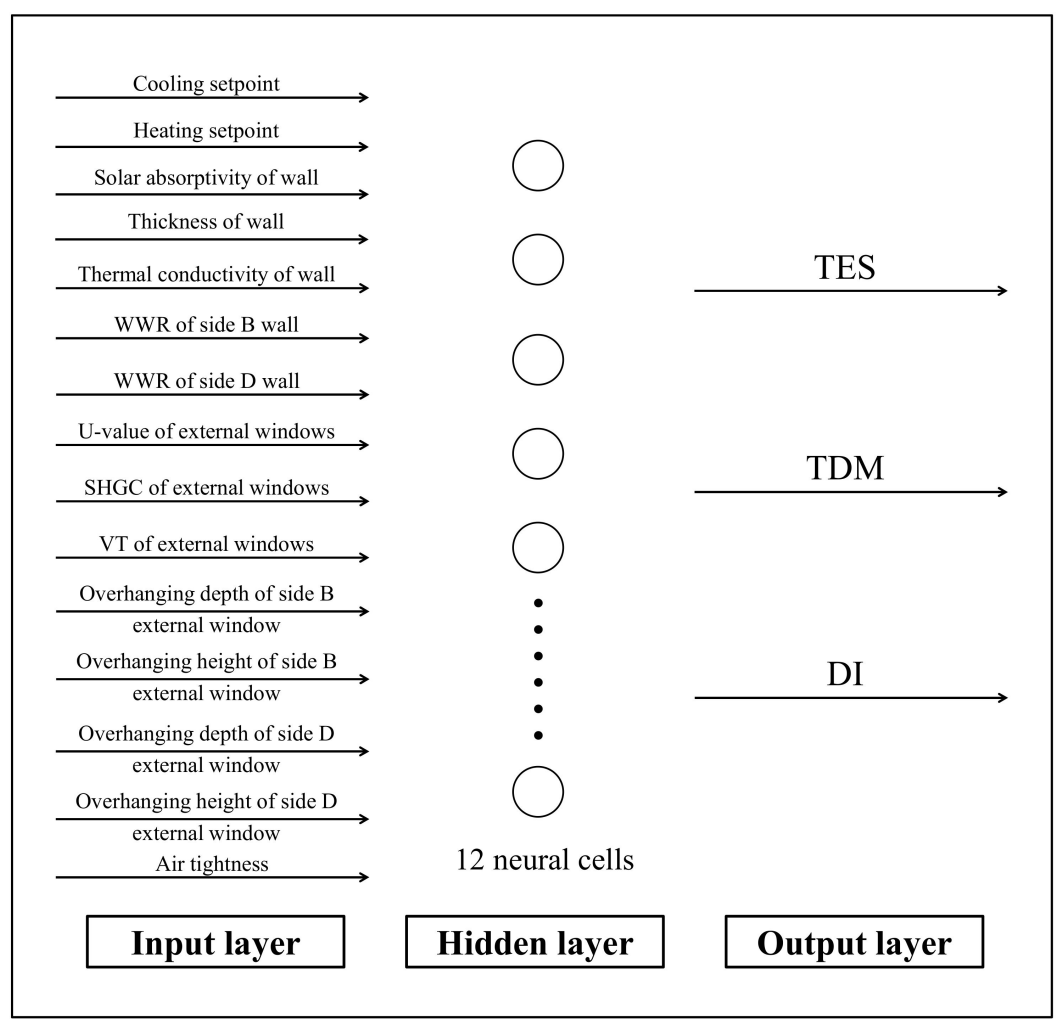

Figure 6. The input and output schematic diagram of ANN model in this study.

Table 3. Hyperparameter setting of the ANN model.

\begin{tabular}{ccc}
\hline Hyperparameters & Search Space of Hyperparameters & $\begin{array}{c}\text { Optimal } \\
\text { Hyperparameters }\end{array}$ \\
\hline Activation function & sigmoid, tanh, relu & relu \\
Hidden layer sizes & $1 ; 2 ; 3 ; \ldots \ldots ; 20$ & 12 \\
Hidden layer numbers & $1 ; 2 ; 3 ; 4$ & 1 \\
\hline
\end{tabular}

Table 4. The mean relative error and $\mathrm{R}^{2}$ values of ANN models with different sample sizes.

\begin{tabular}{ccccc}
\hline Sample Size & TES & PT & DI & $\mathbf{R}^{\mathbf{2}}$ \\
\hline 100 & $8.62 \%$ & $31.42 \%$ & $5.61 \%$ & 0.73 \\
300 & $3.16 \%$ & $12.45 \%$ & $3.30 \%$ & 0.915 \\
500 & $2.31 \%$ & $4.52 \%$ & $2.86 \%$ & 0.971 \\
1000 & $2.26 \%$ & $4.15 \%$ & $2.61 \%$ & 0.970 \\
2000 & $2.49 \%$ & $4.42 \%$ & $2.60 \%$ & 0.970 \\
3000 & $2.48 \%$ & $4.29 \%$ & $2.63 \%$ & 0.969 \\
\hline
\end{tabular}




\subsubsection{Multi-Objective Optimization and Scheme Analysis}

In multi-objective optimization, the trained ANN model can be used as the objective function of the NSGA-II. The objective of this paper is to minimize the TES and maximize the PT and DI. In terms of the NSGA-II, the roulette selection method and two-point cross are selected. In this study, according to [48], some parameters of the NSGA-II are set, including population size, maximum number of iterations, crossover probability and mutation probability, as shown in Table 5.

Table 5. Parameter setting of the NSGA-II.

\begin{tabular}{cc}
\hline Parameter & Value \\
\hline Population size & 50 \\
Maximum number of iterations & 100 \\
Crossover probability & 0.8 \\
Mutation probability & 0.6 \\
\hline
\end{tabular}

The result of multi-objective optimization: the Pareto optimal solution set is shown in Figure 7. For convenience of display, the reciprocal of TES is used instead of TES as the coordinate in the drawing. After optimization, the TES, PT and DI fluctuate in a certain range, at $1622.2-2389 \mathrm{kWh}\left(27-39.8 \mathrm{kWh} / \mathrm{m}^{2}\right)$ per year, $43-81.7 \%$ and $71.1-92.2 \%$, respectively.

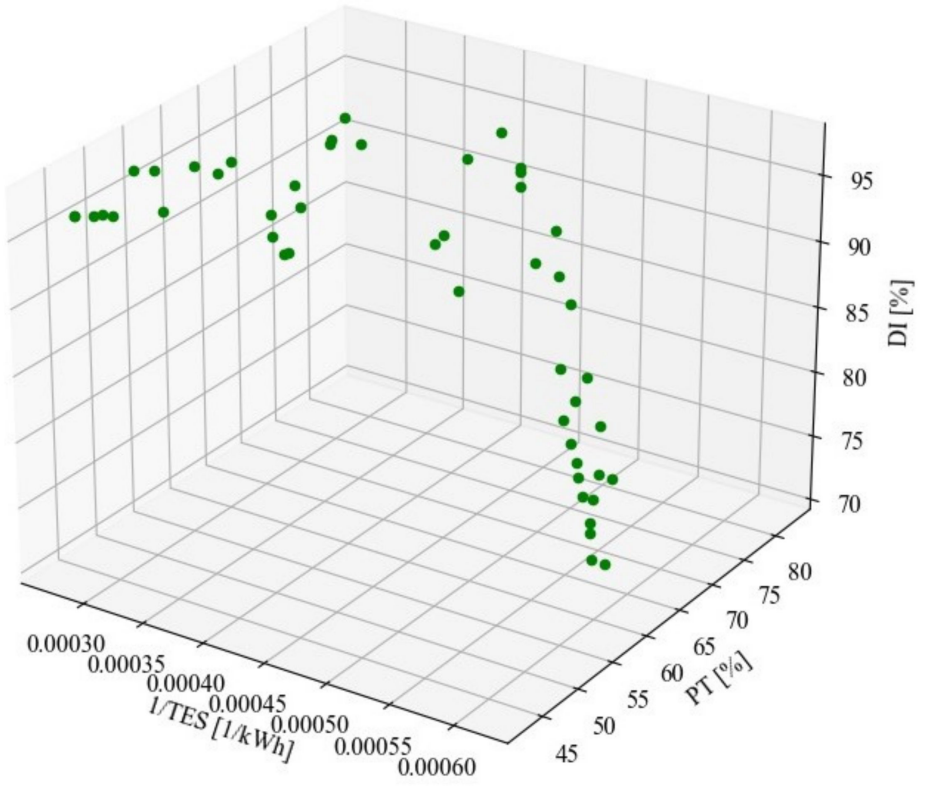

Figure 7. Pareto optimization solution.

This paper analyzes three typical optimal schemes of the Pareto optimal solution: energy optimal, thermal comfort optimal and daylighting optimal solutions, as shown in Table 6. In these three typical optimal schemes, the cooling setpoints and heating setpoints are $28^{\circ} \mathrm{C}$ and $18^{\circ} \mathrm{C}$, respectively. Under this setting, the annual energy consumption of the HVAC system is low. Among the relevant variables of the wall, the solar absorption rate in the optimal scheme of energy and daylighting is 0.1 , but the solar absorption rate in the optimal scheme of thermal comfort is 0.9 . This is mainly because the lower solar energy absorption rate can reduce the classroom heat gain throughout the year, thus reducing energy consumption. The higher solar energy absorption rate can increase the thermal comfort time of the whole year in this study case. In the three schemes, the wall thickness and thermal conductivity are 0.4 and 0.2 , respectively. This is because the thick wall and low thermal conductivity help strengthen classroom insulation and reduce the energy consumption needed for cooling and heating. 
Table 6. Three typical optimal schemes and benchmark scheme.

\begin{tabular}{|c|c|c|c|c|}
\hline Optimization Variables & $\begin{array}{l}\text { Energy } \\
\text { Optimal }\end{array}$ & $\begin{array}{c}\text { Thermal Comfort } \\
\text { Optimal }\end{array}$ & $\begin{array}{l}\text { Daylighting } \\
\text { Optimal }\end{array}$ & $\begin{array}{l}\text { Benchmark } \\
\text { Scheme }\end{array}$ \\
\hline Cooling setpoint $\left({ }^{\circ} \mathrm{C}\right)$ & 28 & 28 & 28 & 26 \\
\hline Heating setpoint $\left({ }^{\circ} \mathrm{C}\right)$ & 18 & 18 & 18 & 18 \\
\hline Solar absorptivity of wall (-) & 0.1 & 0.9 & 0.1 & 0.3 \\
\hline Thickness of wall $(\mathrm{m})$ & 0.4 & 0.4 & 0.4 & 0.24 \\
\hline Thermal conductivity of wall $(\mathrm{W} / \mathrm{mK})$ & 0.2 & 0.2 & 0.2 & 0.6 \\
\hline WWR of side B wall (-) & 0.2 & 0.2 & 0.8 & 0.6 \\
\hline WWR of side D wall (-) & 0.5 & 0.6 & 0.8 & 0.6 \\
\hline U-value of external windows $\left(\mathrm{W} / \mathrm{m}^{2} \mathrm{~K}\right)$ & 0.8 & 0.8 & 0.8 & 2.2 \\
\hline SHGC of external windows (-) & 0.2 & 0.6 & 0.4 & 0.35 \\
\hline VT of external windows (-) & 0.8 & 0.8 & 0.8 & 0.8 \\
\hline Overhanging depth of side B external window (m) & 2 & 2 & 0.1 & 0 \\
\hline Overhanging height of side B external window (m) & 0 & 0 & 0.5 & 0 \\
\hline Overhanging depth of side D external window (m) & 0.1 & 0.1 & 0.1 & 0 \\
\hline Overhanging height of side D external window (m) & 0.5 & 0.5 & 0.5 & 0 \\
\hline Air tightness $(1 / \mathrm{h})$ & 0.05 & 0.05 & 0.05 & 0.3 \\
\hline TES (kWh) & 1622.2 & 2072.3 & 2389 & 2433 \\
\hline PT $(\%)$ & 59.3 & 81.7 & 72.3 & 33.9 \\
\hline DI $(\%)$ & 80.7 & $71.1 \%$ & $92.2 \%$ & $88 \%$ \\
\hline
\end{tabular}

Among the three schemes, the relevant variables of the external window and overhangingrelated variables are quite different. For example, in the daylighting optimal scheme, the WWR of both sides B and D is the maximum value (0.8), and the DI of this scheme is $92.2 \%$, which is significantly larger than those of the other two schemes. However, the TES values are much higher than those of the other two schemes in the daylighting optimal scheme because the large area of external windows inevitably leads to large solar radiation gain and heat exchange in the classroom, affecting the energy consumption of the HVAC system in the classroom. In general, the three optimal schemes have their own advantages and disadvantages, but all of them can be used as design schemes in practical applications.

Due to the lack of evaluation criteria for energy consumption, thermal comfort and daylighting of primary and secondary school classrooms, in order to further measure the optimization effect, this study uses a conventional primary and secondary school classroom designed according to the specifications $[32,46]$ as the benchmark for comparison. The parameter setting and calculation results (calculated by EnergyPlus) are also shown in Table 6. It can be seen that the TES of the benchmark classroom designed according to the specification is greater than three typical optimization schemes, and the PT is less than three typical optimization schemes. This is due to the cooling setpoint, the insulation performance of the envelope and the lack of shading. The DI of the benchmark classroom is higher, but it is still lower than the daylighting optimal scheme.

Overall, compared with the benchmark scheme, in the optimized schemes, TES decreased by $810.8 \mathrm{kWh}$ at most, PT increased by $47.8 \%$ at most and DI increased by $4.2 \%$ at most.

\section{Conclusions}

This paper presents a multi-objective optimization method for classroom design optimization in primary and secondary schools in southern China, which can find the optimal or near-optimal classroom design scheme considering energy, thermal comfort and daylighting under the given conditions. The multi-objective optimization scheme integrates sensitivity analysis, the ANN model and the NSGA-II, which can achieve the efficient and accurate optimization of primary and secondary school classrooms. The main conclusions are as follows:

1. The sensitivity analysis method based on the regression method is used to study the correlation between optimization variables and optimization objectives. The results show that for different sample sizes, the standardization coefficient of each variable is slightly different, but the overall trend is consistent. Among them, wall 
material density, wall specific heat and orientation have little influence on the three optimization objectives $(|\widetilde{\beta}|<0.05)$.

2. The grid search algorithm is used to optimize the hyperparameters of the ANN model, and the influence of different sample sizes is compared. The results show that when the sample size reaches 1000 , the accuracy and stability of the algorithm perform well. At this time, the mean relative error of each optimization objective is $2.26 \%$ (TES), $4.15 \%(\mathrm{PT})$ and $2.61 \%(\mathrm{DI})$, and the $\mathrm{R}^{2}$ value is 0.97 .

3. In this paper, the trained ANN model is coupled with the NSGA-II to achieve multiobjective optimization. After optimization, the TES, PT and DI fluctuate in a certain range, at $1622.2-2389 \mathrm{kWh}$ per year, $43-81.7 \%$ and $71.1-92.2 \%$, respectively.

4. Finally, the benchmark scheme is compared with the optimized design schemes. The results show that the optimization indicators (TES, PT and DI) reflect an improved design scheme. Among them, TES decreased by $810.8 \mathrm{kWh}$ at most, PT increased by $47.8 \%$ at most and DI increased by $4.2 \%$ at most.

Author Contributions: Conceptualization, Y.X. and C.Y.; methodology, Y.J.; software, Y.X.; validation, Y.X., L.S. and H.Q.; formal analysis, H.Q.; investigation, G.W.; resources, G.W.; data curation, Y.X.; writing—original draft preparation, Y.X.; writing—review and editing, Y.X.; visualization, H.Q.; supervision, Y.J.; project administration, C.Y.; funding acquisition, C.Y. All authors have read and agreed to the published version of the manuscript.

Funding: This research was funded by the National Key Research and Development Program of China, grant number No. 2018YFE0116300, the National Natural Science Foundation of China, grant number No. 51708287, the Natural Science Foundation of Jiangsu Province, grant number No. BK20171003, and the Priority Academic Program Development of Jiangsu Higher Education Institutions.

Institutional Review Board Statement: Not applicable.

Informed Consent Statement: Not applicable.

Data Availability Statement: Not applicable.

Conflicts of Interest: The authors declare no conflict of interest.

\section{Nomenclature}

CES Annual cooling energy consumption

Ces Hourly cooling energy consumption

COP Coefficient of performance

DI Percentage of daylight illuminance on the working face is greater than 500 lux during the use period of the whole year

Di Number of hours when the daylighting illumination on the working face is greater than

Di 500 luxduring the use period of the whole year

DX Direct expansion

HES Annual heating energy consumption

Hes Hourly heating energy consumption

HVAC Heating, ventilation and air conditioning

LES Annual lighting energy consumption

Les Hourly lighting energy consumption

Nc Annual cooling hours

$\mathrm{Nh} \quad$ Annual heating hours

$\mathrm{Nl} \quad$ Annual lighting hours

NO Annual zone occupied hours

SHGC Solar heat gain coefficient

PT Percentage of the number of hours with PMV value within the range of -1 to 1 in the total number of hours in the use period of the whole year

Pt the whole year's building use period 


$\begin{array}{ll}\text { TES } & \text { Total annual energy consumption } \\ \text { VRV } & \text { Variable refrigerant volume } \\ \text { VT } & \text { Visible transmittance } \\ \text { WWR } & \text { Window-to-wall ratio } \\ \text { ANN } & \text { Artificial neural network } \\ \text { BP } & \text { Back propagation } \\ \text { GP } & \text { Gaussian process } \\ \text { NSGA-II } & \text { Non-dominated sorting genetic algorithm II } \\ \text { SVM } & \text { Support vector machine } \\ \widetilde{y} & \text { Standardization value of } y \\ \bar{y} & \text { Mean of y } \\ \text { s.d }(y) & \text { Standard deviation of } y \\ \widetilde{x} & \text { Standardization value of } x \\ \bar{x} & \text { Mean of } x \\ \text { s.d }(x) & \text { Standard deviation of } x \\ \beta & \text { Coefficient before standardization } \\ \widetilde{\beta} & \text { Standardization coefficient } \\ \varepsilon & \text { Constant term before standardization } \\ \widetilde{\varepsilon} & \text { Standardization constant term }\end{array}$

\section{References}

1. Xu, Y.; Yan, C.; Liu, H.; Wang, J.; Yang, Z.; Jiang, Y. Smart energy systems: A critical review on design and operation optimization. Sustain. Cities Soc. 2020, 62, 102369. [CrossRef]

2. Attia, S.; Shadmanfar, N.; Ricci, F. Developing two benchmark models for nearly zero energy schools. Appl. Energy 2020, 263, 114614. [CrossRef]

3. Yan, C.; Wang, S.; Xiao, F. A simplified energy performance assessment method for existing buildings based on energy bill disaggregation. Energy Build. 2012, 55, 563-574. [CrossRef]

4. Ma, H.; Lai, J.; Li, C.; Yang, F.; Li, Z. Analysis of school building energy consumption in Tianjin, China. Energy Procedia 2019, 158, 3476-3481. [CrossRef]

5. Wirz-Justice, A.; Skene, D.J.; Munch, M. The relevance of daylight for humans. Biochem. Pharmacol. 2020, 10, 114304. [CrossRef]

6. Li, B.; You, L.; Zheng, M.; Wang, Y.; Wang, Z. Energy consumption pattern and indoor thermal environment of residential building in rural China. Energy Built Environ. 2020, 1, 327-336. [CrossRef]

7. Leccese, F.; Rocca, M.; Salvadori, G.; Belloni, E.; Buratti, C. Towards a holistic approach to indoor environmental quality assessment: Weighting schemes to combine effects of multiple environmental factors. Energy Build. 2021, 245, 111056. [CrossRef]

8. Fan, C.; Xiao, F.; Li, Z.; Wang, J. Unsupervised data analytics in mining big building operational data for energy efficiency enhancement: A review. Energy Build. 2018, 159, 296-308. [CrossRef]

9. Sun, Y. Sensitivity analysis of macro-parameters in the system design of net zero energy building. Energy Build. 2015, 86, 464-477. [CrossRef]

10. Ascione, F.; Bianco, N.; Maria Mauro, G.; Napolitano, D.F. Building envelope design: Multi-objective optimization to minimize energy consumption, global cost and thermal discomfort. Application to different Italian climatic zones. Energy 2019, 174, 359-374. [CrossRef]

11. $\mathrm{Hu}, \mathrm{J} . ; \mathrm{Wu}, \mathrm{J}$. Analysis on the Influence of Building Envelope to Public Buildings Energy Consumption Based on DeST Simulation. Procedia Eng. 2015, 121, 1620-1627. [CrossRef]

12. Zhai, Y.; Wang, Y.; Huang, Y.; Meng, X. A multi-objective optimization methodology for window design considering energy consumption, thermal environment and visual performance. Renew. Energy 2019, 134, 1190-1199. [CrossRef]

13. Chang, S.; Castro-Lacouture, D.; Yamagata, Y. Decision support for retrofitting building envelopes using multi-objective optimization under uncertainties. J. Build. Eng. 2020, 32, 101413. [CrossRef]

14. Pan, L.; Li, K.; Xue, W.; Liu, G. Multi-objective Optimization for Building Performance Design Considering Thermal Comfort and Energy Consumption. In Proceedings of the 35th Chinese Control Conference, Chengdu, China, 27-29 July 2016; pp. 2799-2803.

15. Zhu, L.; Wang, B.; Sun, Y. Multi-objective optimization for energy consumption, daylighting and thermal comfort performance of rural tourism buildings in north China. Build. Environ. 2020, 176, 106841. [CrossRef]

16. Li, J.; Afsari, K.; Li, N.; Peng, J.; Wu, Z.; Cui, H. A review for presenting building information modeling education and research in China. J. Clean. Prod. 2020, 259, 120885. [CrossRef]

17. Rikard, K.; Carin, L. Health and behavior of children in classrooms with and without windows. J. Environ. Psychol. 1992, 12, 305-317.

18. Day, J.K.; McIlvennie, C.; Brackley, C.; Tarantini, M.; Piselli, C.; Hahn, J.; O’Brien, W.; Rajus, V.S.; De Simone, M.; Kjærgaard, M.B.; et al. A review of select human-building interfaces and their relationship to human behavior, energy use and occupant comfort. Build. Environ. 2020, 178, 106920. [CrossRef] 
19. Barrett, P.; Davies, F.; Zhang, Y.; Barrett, L. The impact of classroom design on pupils' learning: Final results of a holistic, multi-level analysis. Build. Environ. 2015, 89, 118-133. [CrossRef]

20. Doulos, L.T.; Kontadakis, A.; Madias, E.N.; Sinou, M.; Tsangrassoulis, A. Minimizing energy consumption for artificial lighting in a typical classroom of a Hellenic public school aiming for near Zero Energy Building using LED DC luminaires and daylight harvesting systems. Energy Build. 2019, 194, 201-217. [CrossRef]

21. Zhang, A.; Bokel, R.; van den Dobbelsteen, A.; Sun, Y.; Huang, Q.; Zhang, Q. Optimization of thermal and daylight performance of school buildings based on a multi-objective genetic algorithm in the cold climate of China. Energy Build. 2017, 139, 371-384. [CrossRef]

22. Acosta-Acosta, D.F.; El-Rayes, K. Optimal design of classroom spaces in naturally-ventilated buildings to maximize occupant satisfaction with human bioeffluents/body odor levels. Build. Environ. 2020, 169, 106543. [CrossRef]

23. Ascione, F.; Bianco, N.; De Masi, R.F.; Mauro, G.M.; Vanoli, G.P. Energy retrofit of educational buildings: Transient energy simulations, model calibration and multi-objective optimization towards nearly zero-energy performance. Energy Build. 2017, 144, 303-319. [CrossRef]

24. Bakmohammadi, P.; Noorzai, E. Optimization of the design of the primary school classrooms in terms of energy and daylight performance considering occupants' thermal and visual comfort. Energy Rep. 2020, 6, 1590-1607. [CrossRef]

25. Yan, C.; Gang, W.; Niu, X.; Peng, X.; Wang, S. Quantitative evaluation of the impact of building load characteristics on energy performance of district cooling systems. Appl. Energy 2017, 205, 635-643. [CrossRef]

26. Wang, R.; Lu, S.; Feng, W. A three-stage optimization methodology for envelope design of passive house considering energy demand, thermal comfort and cost. Energy 2020, 192, 116723. [CrossRef]

27. Chen, J.; Gao, X.; Hu, Y.; Zeng, Z.; Liu, Y. A meta-model-based optimization approach for fast and reliable calibration of building energy models. Energy 2019, 188, 116046. [CrossRef]

28. Yu, W.; Li, B.; Jia, H.; Zhang, M.; Wang, D. Application of multi-objective genetic algorithm to optimize energy efficiency and thermal comfort in building design. Energy Build. 2015, 88, 135-143. [CrossRef]

29. Asadi, E.; Silva, M.G.d.; Antunes, C.H.; Dias, L.; Glicksman, L. Multi-objective optimization for building retrofit: A model using genetic algorithm and artificial neural network and an application. Energy Build. 2014, 81, 444-456. [CrossRef]

30. Zhou, Y.P.; Wu, J.Y.; Wang, R.Z.; Shiochi, S. Energy simulation in the variable refrigerant flow air-conditioning system under cooling conditions. Energy Build. 2007, 39, 212-220. [CrossRef]

31. Zhou, Y.P.; Wu, J.Y.; Wang, R.Z.; Shiochi, S.; Li, Y.M. Simulation and experimental validation of the variable-refrigerant-volume (VRV) air-conditioning system in EnergyPlus. Energy Build. 2008, 40, 1041-1047. [CrossRef]

32. Design Standard for Energy Efficiency of Public Buildings; National Standards of the People's Republic of China. 2015. Available online: http:/ / www.jianbiaoku.com/webarbs/book/73810/1628137.shtml (accessed on 1 September 2021).

33. Zomorodian, Z.S.; Tahsildoost, M.; Hafezi, M. Thermal comfort in educational buildings: A review article. Renew. Sustain. Energy Rev. 2016, 59, 895-906. [CrossRef]

34. Pilechiha, P.; Mahdavinejad, M.; Pour Rahimian, F.; Carnemolla, P.; Seyedzadeh, S. Multi-objective optimisation framework for designing office windows: Quality of view, daylight and energy efficiency. Appl. Energy 2020, 261, 114356. [CrossRef]

35. Konstantzos, I.; Tzempelikos, A.; Chan, Y.-C. Experimental and simulation analysis of daylight glare probability in offices with dynamic window shades. Build. Environ. 2015, 87, 244-254. [CrossRef]

36. Fantozzi, F.; Rocca, M. An Extensive Collection of Evaluation Indicators to Assess Occupants' Health and Comfort in Indoor Environment. Atmosphere 2020, 11, 90. [CrossRef]

37. Ciardiello, A.; Rosso, F.; Dell'Olmo, J.; Ciancio, V.; Ferrero, M.; Salata, F. Multi-objective approach to the optimization of shape and envelope in building energy design. Appl. Energy 2020, 280, 115984. [CrossRef]

38. Pannier, M.-L.; Schalbart, P.; Peuportier, B. Comprehensive assessment of sensitivity analysis methods for the identification of influential factors in building life cycle assessment. J. Clean. Prod. 2018, 199, 466-480. [CrossRef]

39. Tian, W. A review of sensitivity analysis methods in building energy analysis. Renew. Sustain. Energy Rev. 2013, 20, 411-419. [CrossRef]

40. Flannery, M.J.; Rangan, K.P. Partial adjustment toward target capital structures. J. Financ. Econ. 2006, 79, 469-506. [CrossRef]

41. Chen, V.C.P.; Tsui, K.-L.; Barton, R.R.; Allen, J.K. A review of design and modeling in computer experiments. In Handbook of Statistics; Elsevier: Amsterdam, The Netherlands, 2003; Volume 22, pp. 231-261.

42. Roman, N.D.; Bre, F.; Fachinotti, V.D.; Lamberts, R. Application and characterization of metamodels based on artificial neural networks for building performance simulation: A systematic review. Energy Build. 2020, 217, 109972. [CrossRef]

43. Desai, M.; Shah, M. An anatomization on breast cancer detection and diagnosis employing multi-layer perceptron neural network (MLP) and Convolutional neural network (CNN). Clin. eHealth 2021, 4, 1-11. [CrossRef]

44. Østergård, T.; Jensen, R.L.; Maagaard, S.E. A comparison of six metamodeling techniques applied to building performance simulations. Appl. Energy 2018, 211, 89-103. [CrossRef]

45. Monsef, H.; Naghashzadegan, M.; Jamali, A.; Farmani, R. Comparison of evolutionary multi objective optimization algorithms in optimum design of water distribution network. Ain Shams Eng. J. 2019, 10, 103-111. [CrossRef]

46. Code for Design of School; National Standards of the People's Republic of China. 2011. Available online: http:/ /www.jianbiaoku. com/webarbs/book/414/2559815.shtml (accessed on 1 September 2021). 
47. Jihad, A.; Lamia, A. Daylight and Energy Performance Optimization in Hot-Arid Regions: Application and adaptation guide for designers in the UAE. Procedia Manufacturing 2020, 44, 237-244. [CrossRef]

48. Chen, X.; Yang, H.; Zhang, W. Simulation-based approach to optimize passively designed buildings: A case study on a typical architectural form in hot and humid climates. Renew. Sustain. Energy Rev. 2018, 82, 1712-1725. [CrossRef] 